\title{
RANCANG BANGUN SISTEM PENGUKURAN DIAMETER BUTIRAN AIR MENGGUNAKAN FOTODIODA ARRAY DAN TRANSCEIVER nRF24L01+
}

\author{
Awaluddin Awaluddin, Harmadi Harmadi", Marzuki Marzuki \\ Jurusan Fisika, FMIPA, Universitas Andalas, Limau Manis, Padang, 25163 \\ *Korespondensi ke: harmadi@fmipa.unand.ac.id
}

( Diterima: 11 Juli 2019; Direvisi: 27 Juli 2019; Diterbitkan: 01 September 2019 )

\begin{abstract}
ABSTRAK
Telah dilakukan rancang bangun sistem pengukuran diameter butiran air menggunakan fotodioda array dan transceiver nRF24L01+. Sistem pengukuran diameter butiran air terdiri dari laser dioda, fotodioda array, mikrokontroler Arduino Uno R3 dan transceiver nRF24L01+. Pengukuran dilakukan saat butiran air yang berasal dari wadah, dengan variasi ukuran diameter; $1 \mathrm{~mm}, 2 \mathrm{~mm}$, dan $3 \mathrm{~mm}$, melewati sinar laser dan ditangkap oleh fotodioda array. Fotodioda array mengubah cahaya menjadi sinyal listrik dalam bentuk tegangan keluaran dan diolah menggunakan mikrokontroler Arduino Uno R3. Data yang dihasilkan dikirim secara telemetri nirkabel dengan menggunakan transceiver nRF24L01+ dan ditampilkan pada PC dan LCD dalam bentuk hasil pengukuran. Karakterisasi sensor fotodioda array menghasilkan nilai koefisien determinasi $\left(\mathrm{R}^{2}\right)$ sebesar 0,997 dan nilai fungsi transfer yaitu $21,975 e^{-0,004 x}$ yang dimasukkan ke dalam program. Hasil pengujian memperlihatkan semakin rendah tegangan menandakan diameter butiran air hujan semakin besar. Hasil pengukuran diameter butiran air memiliki nilai error rata-rata 0,66. Sistem memiliki jarak pengiriman maksimum $1000 \mathrm{~m}$ tanpa penghalang dan jarak pengiriman minimum $550 \mathrm{~m}$ dengan penghalang.

Kata kunci: fotodioda array, pengukuran butiran air, transceiver nRF24L01+
\end{abstract}

\begin{abstract}
The design of a water droplet diameter measurement system has been carried out using a photodiode array and nRF24L01+ transceiver. The water droplet diameter measurement system consists of a diode laser, a photodiode array, an Arduino Uno R3 microcontroller and an $n R F 24 L 01+$ transceiver. Measurements were made when the water droplets originating from the container with variations in diameter; $1 \mathrm{~mm}, 2 \mathrm{~mm}$, and $3 \mathrm{~mm}$ passed through the laser beam and were captured by the photodiode array. The photodiode array converts light into an electrical signal in the form of an output voltage and is processed using an Arduino Uno R3 microcontroller. The resulting data is sent by wireless telemetry using the $n R F 24 L 01+$ transceiver and displayed on a PC and LCD as the measurement results. Characterization of the photodiode array sensor produces a coefficient of determination $(R 2)$ in the amount of 0.997 and a transfer function value equal to $21,975 e^{-0,004 x}$. The test results show the lower voltage value indicates the larger raindrops diameter. The measurement results of the water droplets diameter have an average error value 0,66. The system has a maximum delivery distance $1000 \mathrm{~m}$ without barrier and a minimum delivery distance $550 \mathrm{~m}$ with barrier.
\end{abstract}

Keywords: photodiode array, measurement of water droplets, nRF24L01+ transceiver 


\section{PENDAHULUAN}

Manusia dapat mengenali pola hujan suatu daerah dengan mengukur besaran fisis hujan seperti kecepatan, diameter dan energi kinetik hujan. Teknik pengukuran butiran air hujan semakin maju. Disdrometer optik merupakan teknik pengukuran butiran air hujan yaitu dengan menggunakan teknik pencitraan optik atau hamburan optik. Teknik pencitraan menggunakan detektor CCD (Change Couple Device) hanya bisa digunakan untuk mendeteksi tingkat cahaya rendah dan memiliki noise yang tinggi. Teknik hamburan optik yang ditangkap dengan menggunakan detektor fotodioda array (PDA) memiliki kelebihan yaitu mampu mendeteksi tingkat cahaya tinggi, memiliki noise yang rendah (Laqua dkk., 1996).

Teknik hamburan optik melibatkan sinar horizontal yang bergerak ke arah penerima cahaya. Butiran air hujan yang melewati sinar laser menyebabkan cahaya terhambur. Atenuasi cahaya yang disebabkan oleh setiap tetes butiran hujan diubah menjadi sinyal listrik oleh penerima yang kemudian dikonversi menjadi ukuran butiran secara akurat dalam bentuk diameter ( Bohren and Huffman, 1983).

Penelitian ini melakukan rancang bangun sistem pengukuran diameter butiran air menggunakan teknik hamburan optik yang dideteksi dengan memakai fotodioda array. Sistem telemetri yang digunakan memakai transceiver nRF24L01+ karena memiliki kelebihan dalam hal pengiriman data secara kontinu dengan Round time trip tercepat 0,003 s (Fajriansyah dkk, 2016). Transceiver nRF24L01+ juga dapat menjangkau jarak $1 \mathrm{~km}$ apabila pada modul transceiver itu ditambahkan antena eksternal (Doc.foc, 2016).

\section{METODE PENELITIAN}

Metode yang digunakan dalam pengukuran diameter butiran air adalah metode hamburan optik. Sinar laser yang dikenai butiran air akan terhambur dan dideteksi oleh fotodioda array. Berkas cahaya tersebut diubah menjadi sinyal listrik dalam bentuk tegangan keluaran dan dikonversi berupa diameter butiran air. Setelah sinyal listrik melewati transmitter nRF24L01+ dan diterima oleh transceiver nRF24L01+, hasilnya akan ditampilkan ke PC dan LCD. Besaran fisis yang muncul pada PC dan LCD berupa nilai diameter ukuran butiran air. Gambar 1 di bawah ini memperlihatkan diagram blok sistem pengukuran diameter butiran air.

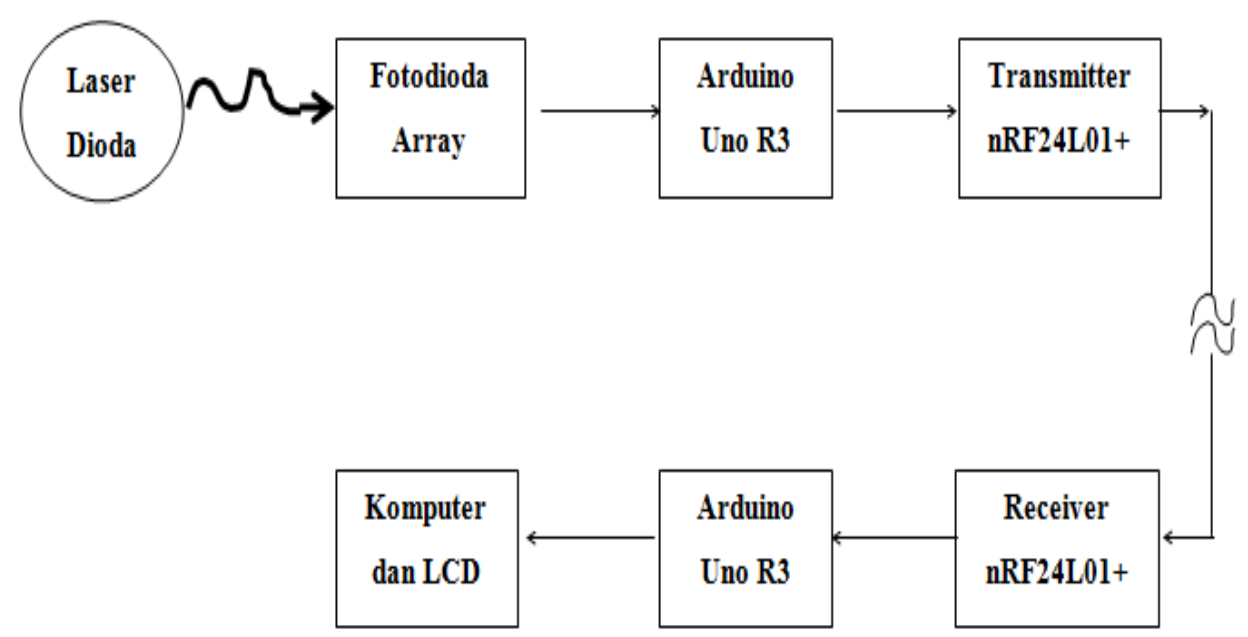

Gambar 1 Diagram blok sistem pengukuran diameter butiran air 
Karakterisasi transceiver nRF24L01+ dilakukan dengan dua variasi yaitu tanpa penghalang dan berpenghalang, seperti diilustrasikan melalui gambar 2 (a) dan gambar 2 (b). Hal ini dilakukan untuk mengetahui seberapa jauh jarak jangkauan maksimum pengiriman kode data.

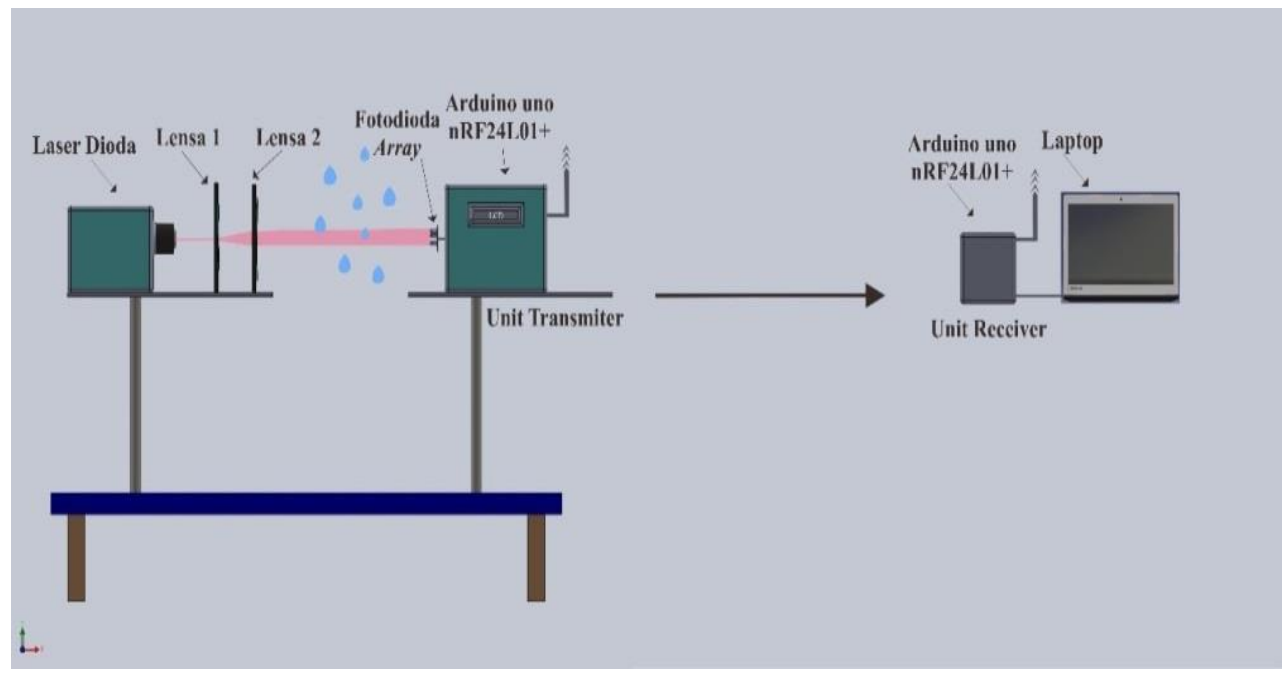

(a)

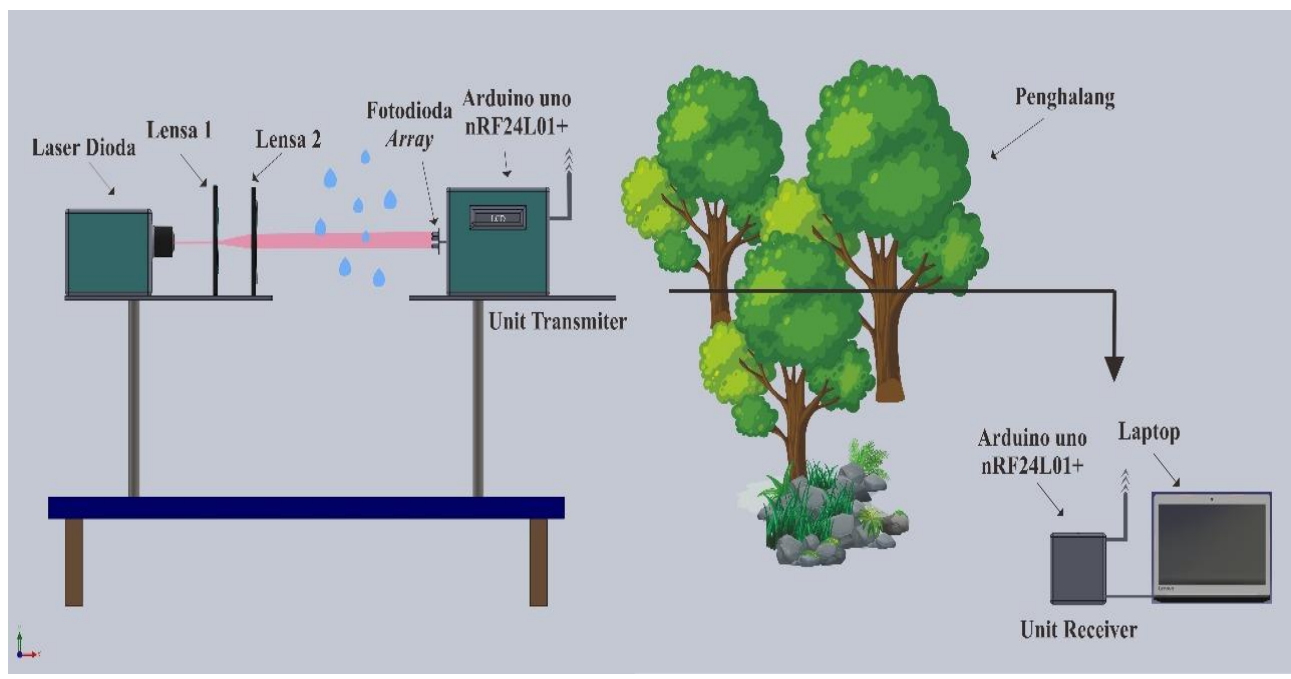

(b)

Gambar 2. (a) Rancangan keseluruhan alat tanpa penghalang (b) Rancangan keseluruhan alat dengan penghalang

\section{HASIL DAN DISKUSI}

\subsection{Uji Alat dengan Glass Ball}

Karakterisasi sensor fotodioda array dilakukan dengan menjatuhkan glass ball pada variasi ukuran yaitu $0,4 \mathrm{~mm}, 1,04 \mathrm{~mm}$ dan $3,03 \mathrm{~mm}$ tepat didepan sensor yang telah disinari laser. Data yang didapatkan merupakan perbandingan diameter glass ball dengan tegangan keluaran sensor. Nilai tegangan keluaran diubah ke Analog to Digital Converter (ADC) dalam bentuk desimal dengan tujuan agar mendapatkan nilai karakterisasi yang 
optimal. Plot data tegangan keluaran sensor terhadap diameter glass ball yang digunakan adalah data karakterisasi optimal yang memiliki koefisien determinasi $\left(\mathrm{R}^{2}\right)$ sebesar 0,997 yang artinya sensor fotodioda array dapat merespons perubahan glass ball ketika dilakukan pengukuran.

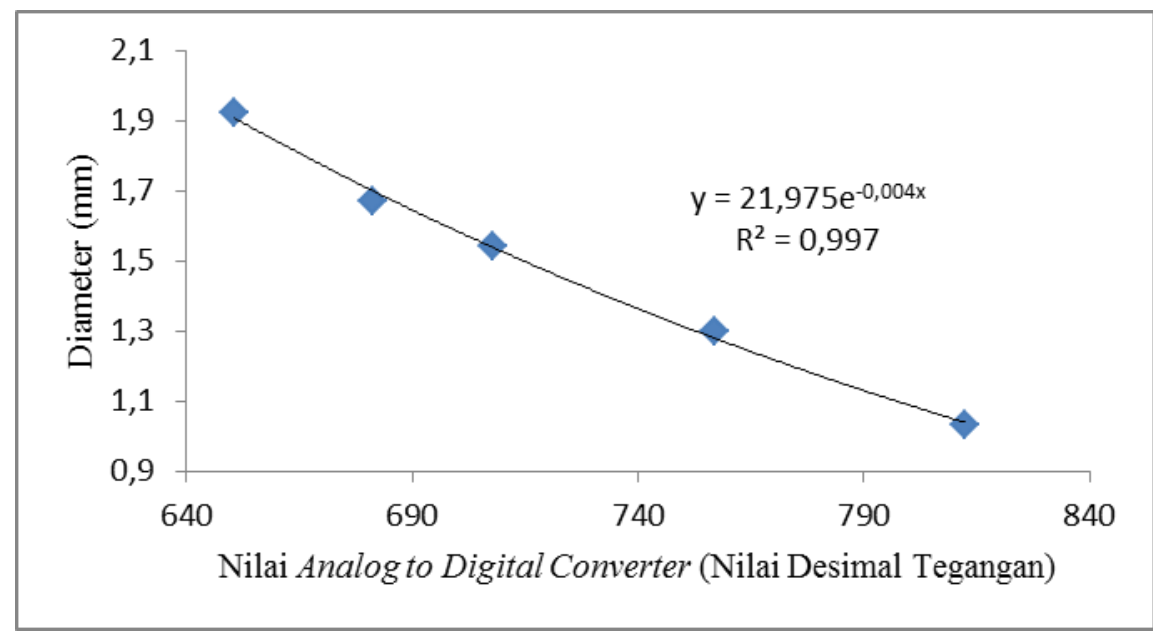

Gambar 3 Hubungan diameter glass ball terhadap nilai Analog to Digital Converter (ADC)

Plot data diameter glass ball terhadap nilai $A D C$ diperlihatkan pada Gambar 3 dengan fungsi transfer yang didapatkan yaitu $=21,975 e^{-0,004 x}$ dengan $\mathrm{R}^{2}=0,997$. Fungsi transfer yang didapatkan ini lalu digunakan sebagai persamaan dalam program pada sensor fotodioda array untuk menghitung diameter butiran air yang terbaca pada alat rancangan.

\subsection{Pengukuran Butiran Air dengan Diameter Lubang Wadah; 1mm, 2 mm dan $3 \mathrm{~mm}$}

Perubahan nilai tegangan disebabkan terhalangnya sensor oleh butiran air. Ketika butiran air melewati berkas laser tepat jatuh pada sensor maka tidak ada cahaya yang dapat ditangkap oleh sensor tersebut sehingga tegangan keluaran yang dihasilkan berkurang. Semakin besar ukuran diameter butiran air maka semakin kecil tegangan keluaran yang dihasilkan (Loffler-Mang dan Joss, 2000). Gambar 4 (a) menunjukkan nilai tegangan mengalami perubahan turun naik terhadap waktu. dengan ketinggian jatuh butiran air pada jarak $50 \mathrm{~cm}$. Ketika butiran air melewati berkas laser tepat jatuh pada sensor maka tidak ada cahaya yang dapat ditangkap oleh sensor tersebut sehingga tegangan keluaran yang dihasilkan berkurang. Hasil pengukuran memperlihatkan semakin kecil tegangan keluaran menandakan semakin besar ukuran diameter butiran air. 


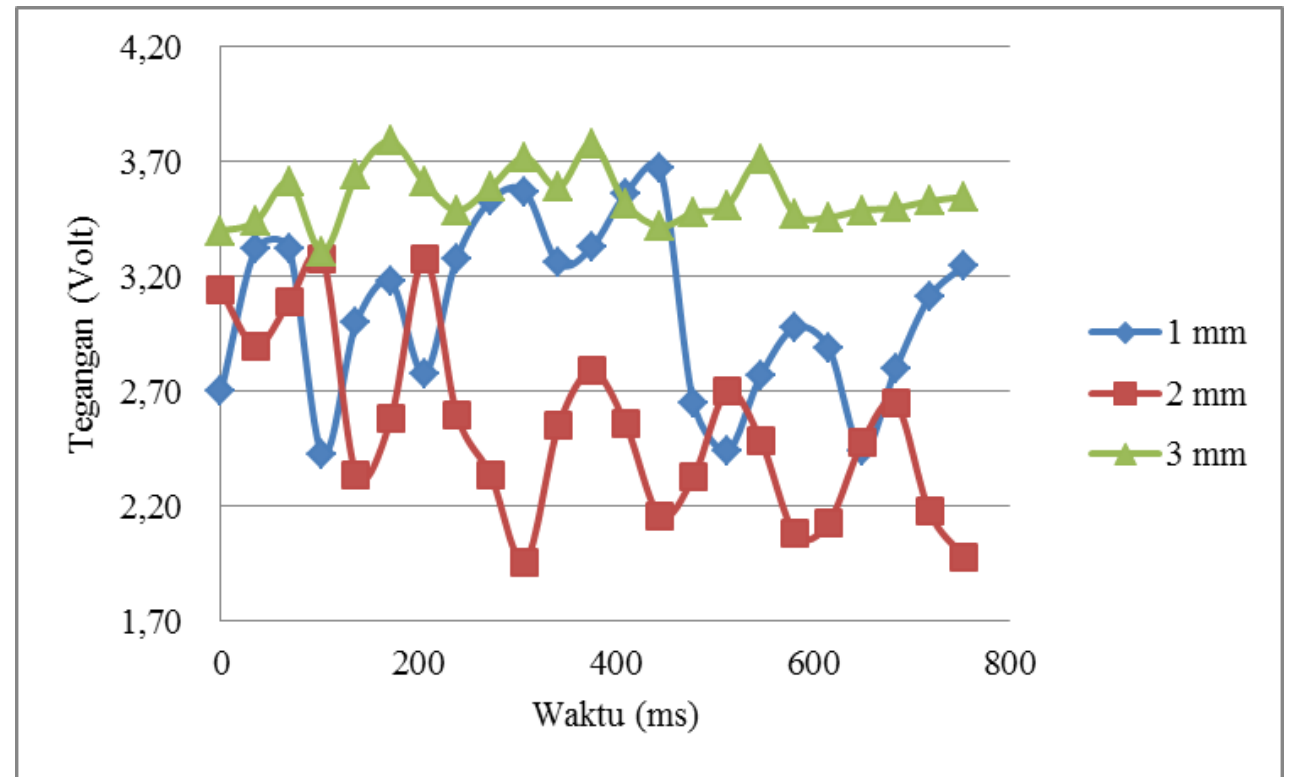

(a)

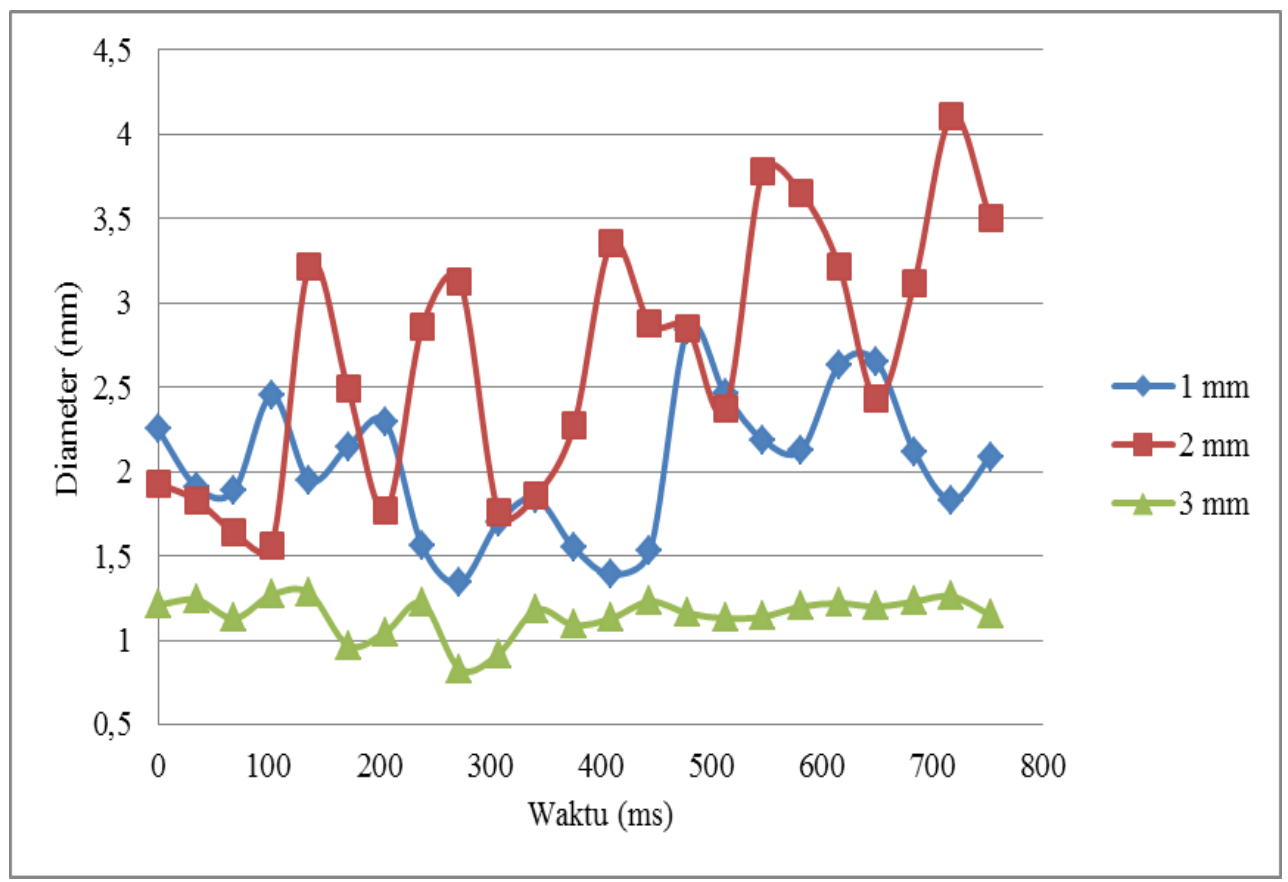

(b)

Gambar 4 Hasil pengukuran (a) Tegangan terhadap waktu (b) Diameter terhadap waktu

Gambar 4 (b) menunjukkan wadah $1 \mathrm{~mm}, 2 \mathrm{~mm}$ dan $3 \mathrm{~mm}$ memiliki diameter butiran hujan rata-rata sebesar 2,03;2,68 mm; dan $1,15 \mathrm{~mm}$. Hasil pengukuran diameter butir air pada wadah $1 \mathrm{~mm}, 2 \mathrm{~mm}$, dan $3 \mathrm{~mm}$ memiliki error rata rata sebesar 0,66. 


\subsection{Karakterisasi Transceiver nRF24L01+}

Karakterisasi ini dilakukan untuk mengetahui seberapa jauh jarak jangkauan maksimum pengiriman kode data outdoor tanpa penghalang dengan kode data outdoor berpenghalang dari unit transmitter - unit receiver ketika hujan turun. Pengiriman data tanpa penghalang dilakukan dengan cara meletakkan rangkaian unit transmitter di salah satu sisi pinggiran sungai dan unit rangkaian lainnya diletakkan di seberang sungai, sedangkan pengujian pengiriman data Outdoor berpenghalang dilakukan dengan cara menyusun semua unit transceiver di salah satu sisi pinggiran jalan di daerah sekitar UNAND dan diukur jarak maksimum pengiriman data dengan kondisi banyak pepohonan. Selanjutnya akan dibandingkan antara outdoor berpenghalang dengan outdoor berpenghalang ketika hujan turun.

Tabel 1. Karakterisasi transceiver nRF24L01+ outdoor ketika hujan tanpa penghalang dan berpenghalang

\begin{tabular}{|c|c|c|c|c|}
\hline $\begin{array}{c}\text { Kode } \\
\text { Pengiriman } \\
\text { (Transmitter- } \\
\text { Receiver) }\end{array}$ & $\begin{array}{c}\text { Jarak tanpa } \\
\text { penghalang } \\
\text { (meter) }\end{array}$ & $\begin{array}{c}\text { Jarak dengan } \\
\text { penghalang } \\
\text { (meter) }\end{array}$ & $\begin{array}{c}\text { Jarak tanpa } \\
\text { penghalang } \\
\text { ketika hujan } \\
\text { (meter) }\end{array}$ & $\begin{array}{c}\text { Jarak dengan } \\
\text { penghalang } \\
\text { ketika hujan } \\
\text { (meter) }\end{array}$ \\
\hline 2004 & 1000 & 550 & 600 & 450 \\
\hline
\end{tabular}

Data karakterisasi Tabel 1 menunjukkan perbandingan jangkauan jarak maksimum pengiriman kode 2004 dari unit transmitter ke unit receiver outdoor tanpa penghalang dengan outdoor tanpa penghalang ketika hujan adalah $400 \mathrm{~m}$, sedangkan Outdoor penghalang dengan Outdoor penghalang ketika hujan adalah 100 m. Pada karakterisasi ini terjadi pengurangan jangkauan jarak pengiriman disebabkan adanya penghalang hujan mengakibatkan terjadinya absorbtion dan scattering .

\section{KESIMPULAN}

Beberapa kesimpulan penelitian ini adalah semakin rendah tegangan menandakan diameter butiran semakin besar dari hasil karakterisasi pada glass ball yang memililiki koefisien regresi $\left(\mathrm{R}^{2}\right)=0,997$. Pengukuran butiran air dengan diameter lubang wadah $1 \mathrm{~mm}, 2 \mathrm{~mm}$ dan $3 \mathrm{~mm}$ pada ketinggian $50 \mathrm{~cm}$ memiliki diameter butiran hujan rata-rata sebesar 2,03 mm; 2,68 mm; dan 1,2 mm serta memiliki error rata-rata sebesar 0,66. Hasil yang didapatkan dari rancang bangun sistem pengukuran butiran air dengan menggunakan tranceiver nRF2401+ memiliki jarak pengiriman maksimum $1000 \mathrm{~m}$ tanpa penghalang dan pengiriman minimum $550 \mathrm{~m}$ dengan penghalang.

\section{UCAPAN TERIMA KASIH}

Penelitian ini didukung oleh hibah Penelitian Terapan Unggulan Perguruan Tinggi (PTUPT) 2019 dari Kementerian Riset Teknologi dan Pendidikan Tinggi Republik Indonesia (kontrak No. T/3/UN.16.17/PT.01.03/PT-Kbc/2019).

\section{DAFTAR PUSTAKA}

Bohren, C. F., \& Huffman, D. R. (1983). Absorption and scattering of light by small particle. Canada: John Wiley and \& Sons, Inc.

Docfoc (2016). 2,4G nRF24L01 wireless module w/PA and LNA. Juli, 2018. http://www.docfoc.com/datasheet-wir020 
Fajriansyah, B., Ichwan, M., \& Susana, R. (2016). Evaluasi karakteristik Xbee Pro dan nRF24L01+ sebagai transceiver nirkabel. Jurnal ELKOMIKA, 4 (1), 83-97.

Laqua, K., Schrader, B., Moore, D. S., \& Vo-Dinh, T. (1996). Analytical chemestry division commission on spectrochemical and other optical procedures for analysis. IUPAC (International Union of Pure and Applied Chemistry), 67 (10), $1745-1760$.

Loffler-Mang, M. \& Joss, J. (2000). An optical disdrometer for measuring size and velocity of hydrometeors. Journal of Atmospheric and Oceanic Technology, 17, 130-139. 